\title{
A Review of Noninvasive Ultrasound Image Processing Methods in the Analysis of Carotid Plaque Morphology for the Assessment of Stroke Risk
}

\author{
Efthyvoulos C. Kyriacou, Member, IEEE, Constantinos Pattichis, Senior Member, IEEE, \\ Marios Pattichis, Senior Member, IEEE, Christos Loizou, Member, IEEE, Christodoulos Christodoulou, \\ Stavros K. Kakkos, and Andrew Nicolaides
}

\begin{abstract}
Noninvasive ultrasound imaging of carotid plaques allows for the development of plaque-image analysis methods associated with the risk of stroke. This paper presents several plaqueimage analysis methods that have been developed over the past years. The paper begins with a review of clinical methods for visual classification that have led to standardized methods for image acquisition, describes methods for image segmentation and denoizing, and provides an overview of the several texture-feature extraction and classification methods that have been applied. We provide a summary of emerging trends in 3-D imaging methods and plaque-motion analysis. Finally, we provide a discussion of the emerging trends and future directions in our concluding remarks.
\end{abstract}

Index Terms-Assessment of stroke, carotid, despekle filtering, plaque imaging, segmentation, texture analysis, ultrasound.

\section{INTRODUCTION}

C ARDIOVASCULAR disease (CVD) is the first leading cause of death and adult disability in the industrial world. According to [1], 80 million American adults have one or more types of CVD, of whom about half are estimated to be age 65 or older. Of all the deaths caused by CVD among adults aged 20 and older, an estimated 6 million are attributed to coronary heart disease and to stroke, with atherosclerosis as the underlying

Manuscript received February 14, 2009; revised July 13, 2009 and December 23, 2009; accepted March 8, 2010. Date of publication April 8, 2010; date of current version July 9, 2010. This work was supported in part by the Cardiovascular Disease Educational and Research (CDER) Trust, U.K. and in part by the CDER Trust, Cyprus.

E. C. Kyriacou is with the Department of Computer Science and Engineering, Frederick University, CY-3080 Limassol, Cyprus (e-mail: e.kyriacou@frederick.ac.cy).

C. Pattichis is with the Department of Computer Science, University of Cyprus, CY-1678 Nicosia, Cyprus (e-mail: pattichi@ucy.ac.cy).

M. Pattichis is with the Department of Electrical and Computer Engineering, The University of New Mexico, Albuquerque, NM 87131-0001 USA (e-mail: pattichis@ece.unm.edu).

C. Loizou is with the Department of Computer Science, School of Sciences, Intercollege, CY-3507 Limassol, Cyprus (e-mail: loizou.c@lim. intercollege.ac.cy).

C. Chistodoulou is with the Department of Computer Science, University of Cyprus, CY-1678, Nicosia, Cyprus, and also with the Department of Computational Intelligence, Cyprus Institute of Neurology and Genetics, 1683 Nicosia, Cyprus (e-mail: cschr2@ucy.ac.cy).

S. K. Kakkos is with the Department of Vascular Surgery, University of Patras Medical School, Patras 26500, Greece (e-mail: kakkosstavros@gmail.com).

A. Nicolaides is Prof. Emeritus at Imperial College, London, SW7 2AZ, U.K., and with the Vascular Screening and Diagnostic Centre, London, W1G 7BZ, U.K., and also with the Cyprus Cardiovascular Disease Educational Research Trust, 2368 Nicosia, Cyprus (e-mail: andisnicolai@gmail.com).

Digital Object Identifier 10.1109/TITB.2010.2047649

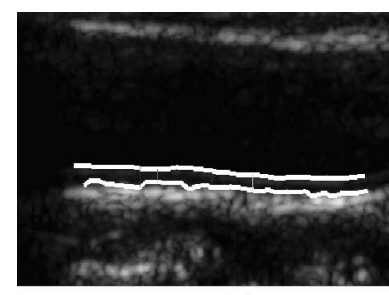

(a)

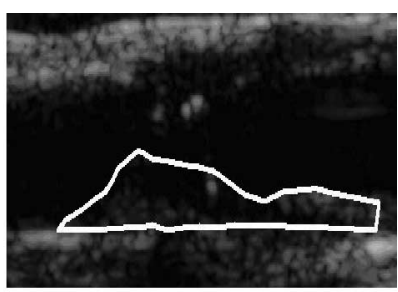

(b)
Fig. 1. Segmentation of CCA images. (a) IMT segmentation image, example where despeckle filtering was applied only in the area of the IMT. (b) Far-wall plaque segmentation results after normalization and despeckling.

cause. Stroke accounted for about one for every 16 deaths in the United States. A recent study by the World Health Organization revealed that by 2015 almost 20 milion people will die from CVDs, mainly from heart disease and stroke [2].

High-Resolution ultrasound has made the noninvasive visualization of the carotid bifurcation possible, and has thus been extensively used in the study of arterial wall changes. Studies include measurement of the thickness of the intima-media complex [intima-media thickness (IMT)], estimation of the severity of stenosis due to atherosclerotic plaques, and plaque characterization in order to assess the risk of stroke [3]-[5] (see Figs. 1 and 2).

Clinical applications of carotid-bifurcation ultrasound include the following:

1) Identification and grading of stenosis of extracranial carotid artery disease often responsible for ischemic strokes, transient ischemic attacks (TIAs), or amaurosis fugax (AF);

2) follow-up after carotid endarterectomy;

3) evaluation of pulsatile neck mass;

4) investigation of asymptomatic neck bruits, where severe internal carotid artery stenosis is used as a predictive factor for future stroke;

5) cardiovascular risk assessment where the presence of carotid bifurcation atherosclerotic plaques is associated with increased cardiovascular mortality [6]-[9];

6) clinical studies on the effect of lipid lowering and other medications on carotid IMT, which includes plaque thickness [10]-[14].

During the past 20 years, the introduction of computer-aided methods and image standardization has improved the objective assessment of carotid plaque echogenicity [15], [16] and 


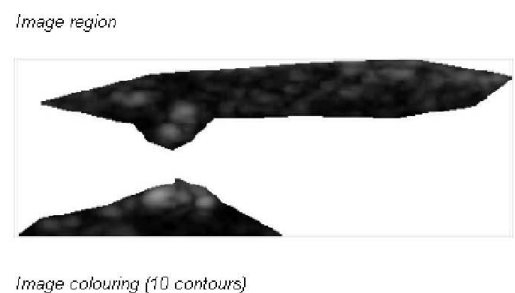

(mage colouring (10 contours)

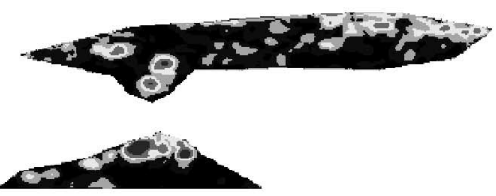

Histogram Kurtosis: 1.807

Gray Scale Median: 38.46

SGLDM-entropy: 7.86

Plaque- type (Geroulakos et al. [31]): 3
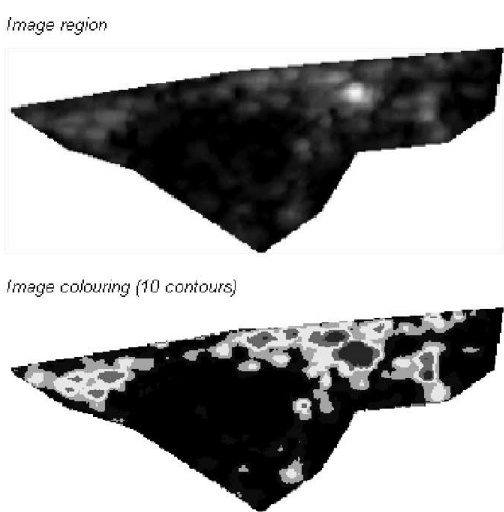

Histogram Kurtosis: 1.813

Gray Scale Median: 26.46

SGLDM-entropy: 7.19

Plaque- type (Geroulakos et al. [31]): 3

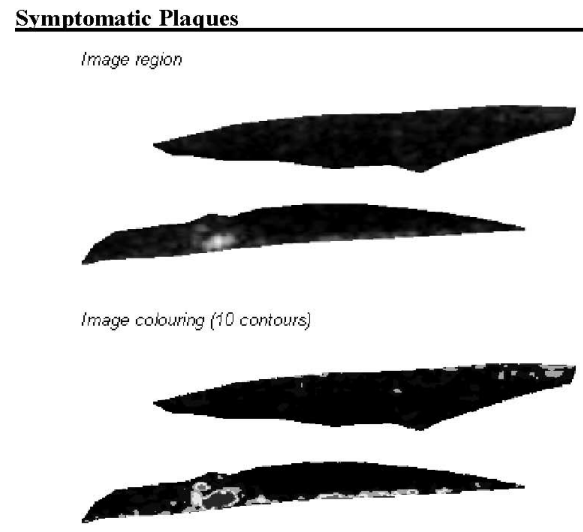

Histogram Kurtosis: 1.875

Gray Scale Median: 13.31

SGLDM-entropy: 5.80

Plaque- type (Geroulakos et al. [31]): 2

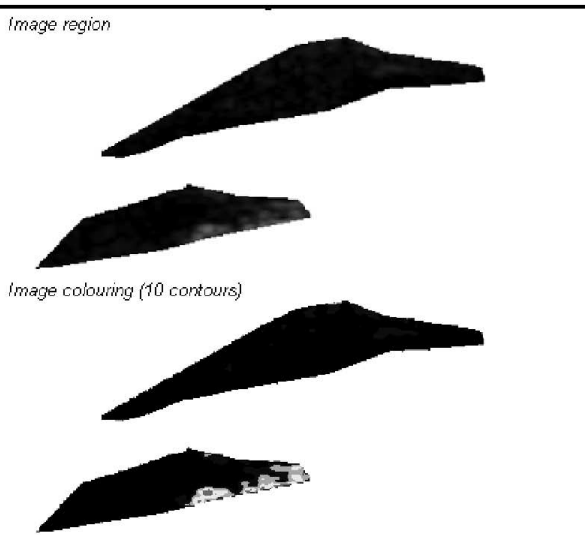

Histogram Kurtosis: 1.906

Gray Scale Median: 7.35

SGLDM-entropy: 5.75

Plaque- type (Geroulakos et al. [31]): 2

Fig. 2. Examples of segmented (a) asymptomatic and (b) symptomatic plaques. Under each plaque, the type of plaque according to [31] and selected texture features are given. (SGLDM: spatial gray-level-dependence matrices.)

heterogeneity [15], [17] and has largely replaced subjective (visual) assessment [3], [18] that had been criticized for its relatively poor reproducibility [19].

In general, computer-aided diagnostic systems require the use of a wide variety of methods that are reviewed in this paper. First, a clinical-image-acquisition protocol is necessary for reducing variability during the acquisition process. Second, an imagenormalization procedure is needed to further standardize the images.

Plaque-image segmentation methods allow us to isolate the region of diagnostic interest. Noise from the extracted plaques can be removed with image despeckling methods. Texture features are subsequently computed over the segmented images. Texture features are then used as inputs to classifiers to provide an overall assessment of the input plaque images.

As an early indicator of CVD, we are also interested in the segmentation and characterization of the intima-media layer. We will provide an extensive summary of intima-media segmentation methods.
Emerging approaches in plaque-ultrasound-image analysis include the recent introduction of 3-D imaging methods, plaque motion analysis, stress and strain imaging, and the use of contrast agents.

A review of visual classification methods is given in Section II. Image segmentation and despeckling methods are reviewed in Section III. A summary of texture-feature extraction and classification methods is given in Section IV. Emerging methods are given in Section V. Concluding remarks on the emerging trends and future directions are given in Section VI.

\section{VisuAl ClASSIFICATION IN THE ASSESSMENT OF ATHEROSCLEROTIC PlaQUES IN ULTRASOUND IMAGING}

High-resolution ultrasound provides information not only on the degree of carotid artery stenosis, but also on the characteristics of the arterial wall, including the size and consistency of atherosclerotic plaques. Several studies have indicated that "complicated" carotid plaques are often associated with ipsilateral neurological symptoms and share common ultrasonic 
TABLE I

Ultrasound CARotid PlaQue HETEROGENEITY AND CLINICAL IMPLICATIONS

\begin{tabular}{|c|c|c|c|c|}
\hline Author & Year & Ref & Ultrasound carotid plaque heterogeneity & Clinical implications \\
\hline O'Donnell Jr et al. & 1985 & {$[20]$} & $\begin{array}{l}\text { Visual classification; distinguished fine vs rough and } \\
\text { random vs regular texture }\end{array}$ & Histology study \\
\hline Aldoori et al. & 1987 & {$[21]$} & Visual classification & Plaque classification \\
\hline Leahy et al. & 1988 & [22] & $\begin{array}{l}\text { Plaques containing echolucent components. } \\
\text { Homogeneous plaques had uniform consistency } \\
\text { suggestive of sclerotic plaques }\end{array}$ & $\begin{array}{l}\text { Heterogeneous plaques were symptomatic and } \\
\text { associated with ipsilateral infarction on CT scan } \\
\text { more frequently than homogenous plaques }\end{array}$ \\
\hline Langsfeld et al. & 1989 & [23] & $\begin{array}{l}\text { Predominantly echolucent plaques with a thin "egg } \\
\text { shell" cap of echogenicity and echogenic plaques with } \\
\text { substantial components of echolucency }\end{array}$ & $\begin{array}{l}\text { Heteroneous plaques more frequently symptomatic. } \\
\text { Heterogeneous plaques became symptomatic more } \\
\text { frequently during follow-up }\end{array}$ \\
\hline Widder et al. & 1990 & [24] & $\begin{array}{l}\text { Visual estimation, plaques being classified into four } \\
\text { categories (homogeneous, slightly or markedly } \\
\text { heterogeneous and non visible) }\end{array}$ & Histology study \\
\hline ECPSG & 1995 & {$[25]$} & Mixed composition & Heterogeneous plaques contained more calcification \\
\hline Kagawa et al. & 1996 & [26] & $\begin{array}{l}\text { Plaques composed of a mixture of hyperechoic, } \\
\text { isoechoic and hypoechoic plaques. Normal intima-media } \\
\text { complex used to define isoechoicity }\end{array}$ & $\begin{array}{l}\text { Heterogeneous lesions consisted of a mixture of } \\
\text { atheroma and fibrosis on histology and demonstrated } \\
\text { calcification more frequently than the homogeneous } \\
\text { ones }\end{array}$ \\
\hline Kardoulas et al. & 1996 & [27] & Mixed echo level pattern & $\begin{array}{l}\text { Association of plaque heterogeneity with symptoms } \\
\text { less consistent in comparison with echolucency }\end{array}$ \\
\hline AbuRahma et al. & 1998 & [28] & $\begin{array}{l}\text { Plaques composed of a mixture of hyperechoic, } \\
\text { isoechoic and hypoechoic plaques. Normal intima-media } \\
\text { complex used to define isoechoicity }\end{array}$ & $\begin{array}{l}\text { Heterogeneous plaques more frequently } \\
\text { symptomatic }\end{array}$ \\
\hline Lal et al. & 2002 & [29] & Ultrasound B-Mode image relation to histology features & Ultrasound and Histology study \\
\hline ACSRS & 2005 & [30] & $\begin{array}{l}\text { Visual classification of high risk plaques based on } \\
\text { follow-up of a group of patients }\end{array}$ & Asymptomatic carotid stenosis follow-up study \\
\hline
\end{tabular}

characteristics, being more echolucent (weak reflection of ultrasound, and therefore, containing hypoechoic structures) and heterogeneous (having both hypoechoic and hyperechoic areas) [25]-[28]. In contrast, "uncomplicated" plaques that are often asymptomatic tend to be of uniform consistency (uniformly hypoechoic or uniformly hyperechoic) without evidence of ulceration [3], [20], [31].

Different classifications of plaque ultrasonic appearance have been proposed in the literature (see Fig. 2). Reilly et al. classified [3] carotid plaques as homogenous and heterogeneous, defining as homogeneous plaques those with "uniformly bright echoes" that are now known as uniformly hyperechoic (type 4) (see next). Johnson et al. classified plaques as dense and soft [32], Widder et al. classified plaques as echolucent and echogenic based on the their overall level of echo patterns [24], while Gray-Weale et al. described four types: type 1 , predominantly echolucent lesions; type 2 , echogenic lesions with substantial (>75\%) components of echolucency; type 3, predominately echogenic with small area(s) of echolucency occupying less than a quarter of the plaque; and type 4 , uniformly dense echogenic lesions [18]. Geroulakos et al. subsequently modified the Gray-Weale classification by using a $50 \%$ area cutoff point instead of $75 \%$ and by adding a fifth type, which, as a result of heavy calcification on its surface, cannot be correctly classified [31] (see also Fig. 2).

In an effort to improve the reproducibility of visual (subjective) classification, a consensus conference has suggested that echodensity should reflect the overall brightness of the plaque with the term hyperechoic referring to echogenic (white) and the term hypoechoic referring to echolucent (black) plaques [33]. The reference structure, to which plaque echodensity should be compared with, should be blood for hypoechoic, the sternomastoid muscle for isoechoic, and bone for hyperechoic plaques. More recently, a similar method has been used by Polak et al. [34].

In the past, a number of workers had confused echogenicity with homogeneity [3]. It is now realized that measurements of texture are different from measurements of echogenicity. The observation that two different atherosclerotic plaques may have the same overall echogenicity, but frequently have variations of texture within different regions of the plaque has been made, as early as 1983 [35]. The term homogeneous should therefore refer to plaques of uniform consistency, irrespective of whether they are predominantly hypoechoic or hyperechoic. The term heterogeneous should be used for plaques of nonuniform consistency, i.e., having both hypoechoic and hyperechoic components (Gray-Weale et al. [18], types 2 and 3). Although O'Donnell et al. in 1985 and Aldoori et al. in 1987 proposed this otherwise simple classification [20], [21], there has been a considerable degree of diversity in terminology used by others, as shown in Table I. Because of this confusion, frequently, plaques having intermediate echogenicity or being complex are inadequately described. For example, echolucent plaques have been considered as heterogeneous [23]. As a reflection of this confusion, a report from the committee on standards for noninvasive vascular testing of the Joint Council of the Society for Vascular Surgery and the North American Chapter of the International Society for Cardiovascular Surgery proposed that carotid plaques should be classified as homogeneous or heterogeneous [36].

Regarding the clinical significance of carotid plaque heterogeneity, it seems that the heterogeneous plaques described in the three studies published in the 1980s (see Table I) include 
hypoechoic plaques. Also, heterogeneous plaques in all studies listed in Table I contain hypoechoic areas (large or small) and appear to be the plaques that are associated with symptoms or, if found in asymptomatic individuals, they are the plaques that subsequently tend to become symptomatic [30].

An important feature of visual classification that has emerged as an important characteristic of unstable--symptomatic plaques in the last years is the juxtaluminal (the site of the plaque near the lumen) location of an echolucent region in heterogenous plaques, which was shown to be an additional marker of increased risk [37].

\section{UltRASOUND-IMAGE PREPROCESSING AND SEGMENTATION}

Visual classification of atherosclerotic plaques on ultrasound is subjective in the sense that if scanning is performed in a relatively dark room, the sonographer reduces the image gain and vice versa. This may explain the relatively poor reproducibility results [19], [34], [38], [39]. In order to overcome this problem, some authors applied linear scaling for image normalization using blood and adventitia as reference points [40].

\section{A. Image Acquisition}

The use of a standardized acquisition protocol has been shown to result in reproducible measurements of overall plaque echogenicity with a high inter and intraobserver reproducibility [39], [41].

Essential guidelines for standardized image acquisition include: 1) maximum dynamic range; 2) low persistence level with high frame rates for improved temporal resolution; 3 ) timegain compensation curve (TGC) sloping through the tissues and vertically through the lumen of the vessel; 4) noise reduction using low gain increased until small amounts of noise appear in the lumen; 5) linear histogram stretching; 6) ultrasound-beam propagation at $90^{\circ}$ to the arterial wall; 7) minimum depth imaging for low attenuation; 8) normalization using clearly visible, hyperechoic adventitia adjacent to the plaque; and 9) acquisition that facilitates subsequent successful image normalization (described next).

\section{B. Normalization}

It has been shown that image normalization reduces variability caused by different gain settings, different operators, and different equipment thus allowing more reproducible gray-scale measurements [15], [16], [41], [42]. In a recent study by Griffin et al. [40], the ultrasound images of the common carotid artery (CCA) were normalized using linear histogram stretching. For 8-bit images, the gray-level value of blood was mapped to a value of 0 , and the gray level of the middle $2 / 4$ th of the adventitia (artery wall) to a value of 190 . Thus, ultrasound-image intensity throughout the image is readjusted according to the gray-scale values of two reference regions (blood and adventitia). Thus, to maintain high reproducibility using image normalization, we need to have a representative sample of the adventitia region. This is accomplished by imaging with the ultrasound- beam propagating at right angles to the adventitia so that it is visible adjacent to the plaque. It has been demonstrated that using this method reproducible measurements of grayscale can be obtained when the same subject is being scanned in different rooms by different ultrasonographers and scanners [39], [41].

\section{Despeckling}

Diagnostic ultrasound-image resolution is significantly limited by speckle noise. Speckle is not truly a noise in the typical engineering sense because its texture often carries useful information about the image being viewed. It is the primary factor that limits the contrast resolution in diagnostic ultrasound imaging, thereby limiting the detectability of small, low-contrast lesions, and making the ultrasound images generally difficult for the nonspecialist to interpret [43]-[45], [47], [56]. Due to the speckle presence, ultrasound experts with insufficient experience may not often draw useful conclusions from the images [6]. Speckle noise also limits the effective application of image processing and analysis algorithms (i.e., edge detection, segmentation) and display in 2-D and volume rendering in 3-D. Therefore, speckle is most often considered as a dominant source of noise in ultrasound imaging and should be filtered out [44]-[46] without affecting important features of the image. In [47], where a review on ultrasound-image segmentation methods has been presented, it was discussed whether speckle should be treated as noise or a feature. It was concluded that from a segmentation perspective, you may chose to remove it or utilize it for the information it contains.

Additionally, there are a number of recent research papers, where ultrasound-imaging despeckling was proposed (e.g., [48]).

As a result, speckle reduces detectability of small, lowcontrast lesions, thus making the ultrasound images generally difficult for the nonspecialist to interpret [43]-[47], [49]-[52], [56]. In a recent study [53], for images of the carotid artery, it was shown that despeckle filtering increases image quality. In addition, normalization combined with speckle reduction filtering also improved the performance of both automated as well as the manual segmentations of the IMT [54] and the plaque [52], [55], and enhanced computer-aided diagnosis [56].

\section{Segmentation}

Several ultrasound-segmentation algorithms have been reviewed in a recent survey by Noble and Boukerroui [47]. Here, we are primarily interested in reporting on recent algorithms that were used for the segmentation of the plaque and the intima layer.

The IMT of the CCA can serve as an early indicator of the development of CVD, like myocardial infarction and stroke. Previous studies indicated that increase in the IMT of the CCA is directly associated with an increased risk of myocardial infarction and stroke, especially in elderly adults without any history of CVD [57]. Therefore, the development and evaluation of new IMT segmentation techniques is of importance.

Table II summarizes various computerized methods that have been developed for ultrasound segmentation of the IMT. 
TABLE II

CAROTID IMT 2-D AND 3-D ULTRASOUND SEGMENTATION TECHNIQUES

\begin{tabular}{|c|c|c|c|c|c|c|c|c|c|}
\hline Author & Year & Ref. & $\begin{array}{l}\text { IMT Segmentation } \\
\text { method }\end{array}$ & $\mathrm{IMT}_{\mathrm{M}}[\mathrm{mm}]$ & $\mathrm{IMT}_{\mathrm{A}}[\mathbf{m m}]$ & S/NS & $\mathbf{N}$ & $\begin{array}{l}\text { AIC/ } \\
\text { NAIC }\end{array}$ & MSI/MCP \\
\hline Wendelhag et al. & 1997 & {$[60]$} & $\begin{array}{l}\text { Dynamic programming } \\
\text { algorithm }\end{array}$ & $0.88 \pm 0.25$ & $0.92 \pm 0.25$ & - & 50 & NAIC & MSI/MCP \\
\hline Liang et al. & 2000 & {$[61]$} & $\begin{array}{l}\text { Multiscale dynamic } \\
\text { programming }\end{array}$ & $0.88 \pm 0.24$ & $0.93 \pm 0.24$ & - & 50 & NAIC & MSI/MCP \\
\hline Mao et al. & 2000 & {$[62]$} & Discrete dynamic contour & - & - & - & 7 & NAIC & MSI \\
\hline Zahalka et al. & 2001 & {$[63]$} & $\begin{array}{l}\text { Deformable models in 3D } \\
\text { images }\end{array}$ & - & - & NS $(95 \%)$ & 69 & NAIC & MSI/MCP \\
\hline Selzer et al. & 2001 & {$[64]$} & $\begin{array}{l}\text { Edge tracking based on } \\
\text { Canny edge detection }\end{array}$ & $0.75 \pm 0.21$ & $0.78 \pm 0.17$ & NS $(97 \%)$ & 24 & NAIC & $\mathrm{MSI} / \mathrm{MCP}$ \\
\hline Cheng et al. & 2002 & {$[58]$} & Snakes (active contours) & - & $0.65 \pm 0.16$ & - & 32 & NAIC & MSI/MCP \\
\hline Gutierez et al. & 2002 & {$[65]$} & $\begin{array}{l}\text { Active contour model } \\
\text { using a Balloon snake }\end{array}$ & $0.63 \pm 0.12$ & $0.72 \pm 0.14$ & - & 30 & NAIC & - \\
\hline Stein et al. & 2005 & {$[66]$} & $\begin{array}{l}\text { Gradient based method } \\
\text { (image gradient) }\end{array}$ & $0.67 \pm 0.15$ & $0.674 \pm 0.12$ & $\begin{array}{l}\text { NS } \\
(95.9 \%)\end{array}$ & 50 & $\mathrm{AIC}$ & MSI/MCP \\
\hline Delsanto et al. & 2007 & {$[67]$} & $\begin{array}{l}\text { Fuzzy C-means algorithm } \\
\text { with snakes }\end{array}$ & $0.77 \pm 0.22$ & $0.71 \pm 0.16$ & NS $(93 \%)$ & 200 & AIC & MSI \\
\hline Loizou et al. & 2007 & [54] & $\begin{array}{l}\text { Snakes (with normalization } \\
\text { and speckle reduction) }\end{array}$ & $0.67 \pm 0.16$ & $0.68 \pm 0.12$ & NS $(96 \%)$ & 100 & AIC & MSI/MCP \\
\hline Faita et al. & 2008 & [68] & $\begin{array}{l}\text { First order absolute } \\
\text { moment edge operator }\end{array}$ & $0.57 \pm 0.14$ & $0.56 \pm 0.14$ & NS $(96 \%)$ & 150 & AIC & MSI \\
\hline
\end{tabular}

A gradient-based segmentation method proposed in [66] produced large variability in the measurements, whereas the methods in [67] and [68] were allowing manual corrections. Recent commercial systems, which support IMT segmentation, include snakes-based segmentation in [58] and using a contouring approach in [59].

In a recent study [54], we proposed a snake's segmentation method (Williams and Shah) with manual initialization [see Fig. 1(a)]. In Fig. 1(a), the despeckle filter LSMV (local statistics mean filter based on the mean and the variance of the pixel values in each sliding moving window) was iteratively applied for five times with a moving pixel window of $7 \times 7$ pixels [54], [56]. We did not find significant differences between the manual and automated IMT measurements. Furthermore, it was shown that when normalization and despeckle filtering are applied prior to IMT or plaque segmentation, the automated segmentation measurements are in better agreement with manual measurements [54]. Furthermore, the estimation and positioning of the initial snake contour may sometimes result to segmentation errors. This should be placed as close as possible to the area of interest, otherwise it may be trapped into local minima or false edges and converge to a wrong location. In the present study in less than $5 \%$ of the cases, the positioning of the initial snake contour was not calculated correctly. The applicability of the proposed snakes border detection in cases, where the IMT is larger than $1.4 \mathrm{~mm}$, is not possible, i.e., because for larger IMT, a different initialization procedure, based on plaque segmentation, should be followed as proposed in [55].

The risk of stroke increases with the severity of carotid stenosis and is reduced after carotid endarterectomy [15], [16]. The degree of internal carotid stenosis is the only well-established measurement that is used to assess the risk of stroke [16]. Indeed, it is the only criterion at present used to decide whether carotid endarterectomy is indicated or not [22], [69]. The need for the accurate segmentation of the atherosclerotic carotid plague in ultrasound imaging in order to assess the degree of stenosis is, therefore, a very important task.

In Table III, we summarize several recent methods for segmenting carotid plaques. In summary, we have segmentation methods based on edge detection and snakes [55].

A user-independent plaque characterization and IMTsegmentation method was proposed in [72], based on interest-identification stage, gradient-segmentation stage, and a contour-refinement stage, using deformable parametric model. The overall accuracy of the system determined as normalized error was overall to $8 \%$.

In a recent study [55], we proposed a snake-segmentation method based on the Lai and Chin snake for segmenting the atherosclerotic-carotid plaque. The initial contour estimation was carried out without user interaction using the blood-flow image. It was also shown that normalization and speckle-reduction filtering improves the outcome of the plaque segmentation. The user was able to interact and correct the segmentation results manually. A limitation of the proposed method includes the presence of acoustic shadowing together with strong speckle noise, which hinders the visual and automatic analysis in ultrasound images. Furthermore, only vessels without atherosclerotic plaques were segmented in this study.

Fig. 1(b) shows segmentation results of the plaque at the far wall of the CCA, where normalization and speckle-reduction 
TABLE III

Recent Segmentation Techniques for CARotid Plaque 2-D AND 3-D Ultrasound

\begin{tabular}{|c|c|c|c|c|c|c|}
\hline Author & Year & Ref. & Plaque Segmentation method & $\mathbf{N}$ & $\mathbf{R} / \mathbf{T P F}$ & S/FPF \\
\hline Zahalka et al. & 2001 & {$[63]$} & Deformable models in $3 \mathrm{D}$ images & 69 & $0.95 \%$ & \\
\hline Hamou et al. & 2004 & {$[70]$} & $\begin{array}{l}\text { Morphological based in } 2 \mathrm{D} \text {, based on histogram } \\
\text { equalization, canny, and morphology. }\end{array}$ & 2 & - & - \\
\hline Abdel-Dayen et al. & 2004 & {$[71]$} & $\begin{array}{l}\text { Morphological approach for } 2 \mathrm{D} \text { images based on } \\
\text { speckle reduction contour quantization, and } \\
\text { morphological contour detection. }\end{array}$ & 2 & - & - \\
\hline Delsanto et al. & 2006 & {$[72]$} & $\begin{array}{l}\text { Area of interest identification, gradient } \\
\text { segmentation, and contour refinement by a } \\
\text { deformable parametric model (2D). }\end{array}$ & 45 & 0.92 & - \\
\hline Loizou et al. & 2007 & {$[54]$} & $\begin{array}{l}\text { Snakes with initial contour estimation, } \\
\text { normalisation and speckle filtering in 2D }\end{array}$ & 80 & $\begin{array}{l}0.821 \\
82.7 \%\end{array}$ & $\begin{array}{l}0.94 / \\
5.86 \%\end{array}$ \\
\hline Guerrero et al. & 2007 & [73] & Star Kalman Algorithm (2D) & - & - & - \\
\hline Slabaugh et.al. & 2009 & [74] & Region based active contour segmentation (2D) & - & - & - \\
\hline
\end{tabular}

filtering was applied prior to segmentation. There was no significant difference between the manual and the snakes segmentation regions.

In [73], a method based on a Star-Kalman algorithm was used to determine vessel contours and ellipse parameters using an extended Kalman filter with an elliptical model. The segmentation and tracking were implemented in real time and validated using simulated ultrasound data with known features and real data, for which expert segmentation was performed. Results indicate that mean errors between segmented contours and expert tracings are on the order of $1 \%-2 \%$ of the maximum feature dimension, and that the transverse cross-sectional vessel area, as computed from estimated ellipse parameters determined by the algorithm, is within $10 \%$ of that determined by experts.

\section{Ultrasound-Image ANALYsis: FEATURE EXTRACTION AND CLASSIFICATION}

\section{A. Feature Extraction}

Following segmentation, we extract features from the region of interest (see Figs. 1(b) and 2). In what follows, we provide a summary of the extracted feature sets.

Earlier studies have been primarily focused on basic statistical features, such as the gray-scale medial (GSM), the mean, the median, the standard deviation, skewness, and kurtosis [16], [37], [75]-[77]. In these earlier studies, the GSM was found to be very successful in differentiating between symptomatic and asymptomatic cases [16], [76]. Depending on the image preprocessing method, threshold values for the GSM were provided for differentiating between symptomatic and asymptomatic cases. Here, brighter plaques tended to be asymptomatic (see Table IV and Section IV-B, see also Fig. 2).

More extensively, histogram features were later used to provide plaque-signature vectors [57], [78]-[80]. Similarly, histograms of grayscale occurrences at different angles and distances (correlograms, not the same as used in spatial statistics) were reported in [57].

Standard texture features have been extensively used for the classification of carotid plaques [57], [78], [81]-[83]. An early discussion of standard texture features can be found in [84]. The most commonly used texture features include: 1) spatial graylevel-dependence matrices (SGLDM); 2) gray-level-difference statistics; 3) neighborhood gray-tone difference matrix; 4) statistical feature matrix; 5) laws texture energy measures; and 6) fractal-dimension texture analysis. A summary of the basic differences between texture characteristics from symptomatic and asymptomatic cases is discussed in [78] and also illustrated in Fig. 2.

More recently, we have used morphological features for plaque-image characterization [57], [82], [83]. The most successful morphological features were based on a multilevel decomposition, associated with different plaque image components. In the multilevel approach, each normalized plaque is thresholded at three different intensity ranges (low, medium, and high). The darkest (low) components are associated with unstable plaque components, such as lipid and hemorrhages. On the other hand, more stable plaque components are captured at higher brightness levels. For each one of the three cases, we compute pattern spectra to provide size distributions of the plaque components [85], [86]. We then use the pattern spectra as texture features for classification.

\section{B. Classification}

Several classification techniques were used for the classification of the carotid plaques. We have neural classifiers, such as the self-organizing map (SOM) [57], [78], the back propagation (BP) [81], the radial basis function (RBF), the probabilistic neural network (PNN) [82], [83]. More recently, we see classification based on support vector machines (SVMs) [82], [83]. In addition, we also have research done with statistical classifiers, such as the $K$-nearest neighbor (KNN) [57], [78] or simple statistical analysis of the plaque characteristics [75]-[77], [87]. For measuring performance, the leave-one-out method has been commonly used together with receiver-operating characteristic (ROC) analysis [78], [81]. We provide a brief survey of a number of classification studies and comment on the association between the extracted plaque characteristics and cerebrovascular symptoms. These studies are further tabulated in Table IV. 
TABLE IV

Ultrasound CARotid PlaQue Classification Studies

\begin{tabular}{|c|c|c|c|c|c|}
\hline Author & Year & Ref. & Short description of study & $\mathbf{N}$ & Score \\
\hline \multicolumn{6}{|c|}{ Statistical Analysis Studies } \\
\hline Geroulakos et al. & 1994 & {$[75]$} & $\begin{array}{l}\text { Tested the hypothesis that the ultrasonic characteristics of carotid artery plaques } \\
\text { were closely related to symptoms. An association was found of echolucent plaques } \\
\text { with symptoms and cerebral infractions, which provided further evidence that } \\
\text { echolucent plaques are unstable and tend to embolize. }\end{array}$ & 105 & \\
\hline El-Barghouty et al. & 1995 & {$[76]$} & $\begin{array}{l}\text { In a study with } 94 \text { plaques, the gray scale median }(G S M) \text { of the ultrasound plaque } \\
\text { image was used for the characterization of plaques as echolucent }(G S M \leq 32) \text { and } \\
\text { echogenic }(G S M>32) \text {. An association between carotid plaque echolucency and } \\
\text { the incidence of cerebral computed tomography }(\mathrm{CT}) \text { brain infractions was } \\
\text { reported. }\end{array}$ & 94 & \\
\hline Iannuzzi et al. & 1995 & {$[77]$} & $\begin{array}{l}\text { Identified significant relationships between carotid artery ultrasound plaque } \\
\text { characteristics and ischemic cerebrovascular events. The features that were more } \\
\text { consistently associated with TIAs were low echogenicity of carotid plaques, } \\
\text { thicker plaques, and presence of longitudinal motion. }\end{array}$ & 549 & \\
\hline Elatrozy et al. & 1998 & [16] & $\begin{array}{l}\text { A study where } 80 \text { patients were examined and reported that plaques with GSM }<40 \\
\text { are more related to ipsilateral hemispheric symptoms. }\end{array}$ & 80 & \\
\hline Wilhjelm et al. & 1998 & {$[87]$} & $\begin{array}{l}\text { In a study with } 52 \text { patients scheduled for endarterectomy presented a quantitative } \\
\text { comparison between subjective classification of the ultrasound images, first and } \\
\text { second order statistical features, and a histological analysis of the surgically } \\
\text { removed plaque. Some correlation was found between the three types of } \\
\text { information where the best performing feature was found to be the contrast. }\end{array}$ & 52 & \\
\hline Rakebrandt et al. & 2000 & [79] & $\begin{array}{l}\text { This study aimed to construct parametric images of B-scan texture and assess their } \\
\text { potential for predicting plaque morphology. Sequential transverse in vitro scans of } \\
10 \text { carotid plaques, excised during endarteectomy, were compared with } \\
\text { macrohistology maps of plaque content. }\end{array}$ & 10 & \\
\hline Asvestas et al. & 2002 & {$[88]$} & $\begin{array}{l}\text { A pilot study with } 19 \text { carotid plaques. Indicated a significant difference of the } \\
\text { fractal dimension between the symptomatic and asymptomatic groups. }\end{array}$ & 19 & \\
\hline \multicolumn{6}{|c|}{ Intelligent Diagnostic Systems } \\
\hline Christodoulou et al. & 2003 & $\begin{array}{l}{[78]} \\
{[57]}\end{array}$ & $\begin{array}{l}\text { A study with } 230 \text { plaque images where ten different texture feature sets were } \\
\text { extracted. The plaques were classified into symptomatic or asymptomatic using the } \\
\text { SOM and KNN classifiers and combining techniques. Furthermore a carotid } \\
\text { plaque image retrieval system was developed, based on texture, histogram and } \\
\text { correlogram features. }\end{array}$ & 230 & $73 \%$ \\
\hline Mougiakakou et al. & 2007 & [81] & $\begin{array}{l}\text { A study with } 108 \text { plaque images where first-order statistical features and Laws' } \\
\text { texture energy measures with the neural network back propagation algorithm were } \\
\text { used. An overall accuracy of } 99.1 \% \text { in the classification into symptomatic or } \\
\text { asymptomatic plaques was reported. }\end{array}$ & 108 & $99 \%$ \\
\hline Holdfeldt et al. & 2007 & {$[89]$} & $\begin{array}{l}\text { In this master thesis an automated system was developed for the classification of } \\
\text { echogenic Vs echolucent plaques using an adaptive threshold. The plaques were } \\
\text { labeled as echogenic or echolucent by the human expert. }\end{array}$ & 97 & $91 \%$ \\
\hline Kyriacou et al. & 2007 & $\begin{array}{l}{[82]} \\
{[83]}\end{array}$ & $\begin{array}{l}\text { In this work an integrated system for the assessment of the risk of stroke based on } \\
\text { clinical risk factors and non-invasive investigations and carotid plaque texture } \\
\text { analysis and multilevel binary and gray scale morphological, analysis in the } \\
\text { assessment of atherosclerotic carotid plaques. }\end{array}$ & 274 & $73 \%$ \\
\hline
\end{tabular}

Geroulakos et al. [75] tested the hypothesis that the ultrasonic characteristics of carotid artery plaques are closely related to symptoms and the plaque structure may be an important factor in producing stroke, perhaps more than the degree of stenosis. In this paper, the authors categorized the carotid plaques into four ultrasonic types: echolucent, predominately echolucent, predominately echogenic, and echogenic. An association was found of echolucent plaques with symptoms and cerebral infractions, which provided further evidence that echolucent plaques are unstable and tend to embolize.

El-Barghouty et al. [76] in a study with 94 plaques reported an association between carotid plaque echolucency and the incidence of cerebral computed tomography (CT) brain infractions. The GSM of the ultrasound-plaque image was used for the characterization of plaques as echolucent $(\mathrm{GSM} \leq 32)$ and echogenic (GSM > 32).

Iannuzzi et al. [77] analyzed 242 stroke and 336 TIA patients and identified significant relationships between carotid artery ultrasound-plaque characteristics and ischemic cerebrovascular events, respectively. The results suggested that the features more strongly associated with stroke were either the occlusion of the ipsilateral carotid artery or wider lesions and smaller minimum residual lumen diameter. The features, which were more consistently associated with TIAs, were low echogenicity of carotid plaques, thicker plaques, and the presence of longitudinal motion.

Elatrozy et al. [16] examined 96 plaques (25 symptomatic and 71 asymptomatic) from 80 patients with more than $50 \%$ internal 
carotid artery stenosis. They reported that plaques with GSM $<40$, or with a percentage of echolucent pixels greater than $50 \%$ were good predictors of ipsilateral hemispheric symptoms related to carotid plaques. As echolucent pixels were defined, pixels with gray level values below 40 .

Wilhjelm et al. [87] in a study with 52 patients scheduled for endarterectomy, presented a quantitative comparison between subjective classifications of the ultrasound images, first- and second-order statistical features, and a histological analysis of the surgically removed plaque. Some correlation was found between the three types of information, where the best-performing feature was found to be the contrast.

Rakebrandt et al. [79] demonstrated that texture analysis of B-mode ultrasound images of carotid plaques using histogram features (in conjunction with co-occurrence matrices, fractal models, and first-order statistics) can predict plaque composition using histological methods.

Asvestas et al. [88] in a pilot study with 19 carotid plaques indicated a significant difference of the fractal dimension between the symptomatic and asymptomatic groups. Moreover, the phase of the cardiac cycle (systole/diastole) during which the fractal dimension was estimated had no systematic effect on the calculations. This study suggests that the fractal dimension could be used as a single determinant for the discrimination of symptomatic and asymptomatic subjects.

Kakkos et al. [80] used histogram measures and found out that the percentage of pixels below 10 and gray scale median between 1 to 25 (i.e., the darkest parts of the plaque) were associated with symptoms (AF, TIA, and stroke).

In most of the aforementioned studies, the characteristics of the plaques were usually defined subjectively or using simple statistical measures, and the association with symptoms was established through simple statistical analysis. In the following studies, intelligent diagnostic systems were developed for the automatic classification of plaques into symptomatic or asymptomatic.

Christodoulou et al. [78] extracted a total number of 61 texture and shape features from 230 ultrasound-plaque images, and these features were analyzed using a multifeature multiclassifier methodology. A diagnostic yield of $73.1 \%$ was reported, thus indicating that it is possible to identify a group of patients at risk of stroke based on texture features and neural networks. In content-based image-retrieval study, Christodoulou et al. [57] showed that correlograms gave slightly better performance than traditional texture features.

Mougiakakou et al. [81], in a study with 108 plaque images, extracted first-order statistical features and Laws' texture energy measures that were classified with a neural network BP algorithm. They claimed an overall accuracy of $99.1 \%$ in the classification of symptomatic and asymptomatic plaques.

Holdfeldt [89] developed an automated system for the classification of echogenic versus echolucent plaques using heuristics and an adaptive threshold. The plaques were labeled as echogenic or echolucent by a human expert. Holdfieldt reported that the system could correctly identify the plaques with a success rate of $91 \%$.
Kyriacou et al. [83], [86] describe an integrated system for the assessment of the risk of stroke based on clinical risk factors (noninvasive) and carotid plaque texture analysis. The system was validated on 274 images. It included semiautomatic plaque segmentation, morphological image analysis, and classification using multiple classifiers. For image features, the system compared the use of a new multilevel morphological decomposition (see Section IV-A) versus standard gray-scale morphological analysis. For classification, comparisons were made between a PNN and a SVM with RBF kernels. The best classification result was at $73.4 \%$ using the SVM classifier with multilevel morphological features.

\section{EMERGING STUdIES}

\section{A. 3-D Studies}

The use of 3-D techniques has primarily focused on measuring volume changes through time to monitor disease progression [90]-[92]. Landry et al. [90] demonstrated that plaque volume change can be reliably measured using 3-D ultrasound. They showed that a $20 \%-35 \%$ change can be measured with $95 \%$ confidence for plaques of volume $<100 \mathrm{~mm}^{3}$. For larger plaques (volume $>100 \mathrm{~mm}^{3}$ ), with $95 \%$ confidence, they showed that we can measure finer changes of the order of 10\%-20\%, respectively. Chiu et al. [91] developed a 3-D segmentation method for measuring the combined thickness of the plaque, the intima, and media (vessel wall plus plaque thickness or VWT). The authors proposed the use of 3-D VWT and VWT-change maps for identifying disease progression in relations to disturbances of flow. The authors extended their work in [92], where they measured VWT volume changes for assessing and monitoring carotid artery disease.

\section{B. Motion}

The majority of motion studies are focused on the use of 2-D ultrasound. However, Meairs and Hennerici [93] reported on an important early study on the use of 4-D ultrasound for motion estimation. Using 45 patients, the authors showed that asymptomatic plaques maintained plaque-surface motion vectors that were approximately equal to motion vectors of the internal carotid artery. In contrast, plaques from symptomatic patients exhibited independent motion with larger surface motion.

For B-mode ultrasound, Murillo et al. [94] computed motion trajectories over the plaques and used the results to develop realistic, synthetic models of plaque motion. Murray et al. [95] developed a new motion estimation model and demonstrated that it can provide for dense estimates over the entire cardiac cycle. In [96], Golemati et al. used tissue mimicking phantoms and synthetic motion models to verify motion estimation using block matching and optical flow methods. A mathematical model was developed by Golemati et al. in [97], and the results were compared with the block-matching software developed in [98].

\section{Stress-Strain}

Scmitt et al. [99] proposed the use of elastography for measuring stiffening and mechanical interactions between plaque 
structures. Here, we note that research on improving motion estimation can also benefit future work in this area.

\section{CONCLUding REMARKS AND FUtURE DiRECTIONS}

The majority of plaque-image analysis studies are focused on the development of 2-D ultrasound systems. In general, these studies present effective methods for image segmentation, image despeckling, and texture feature extraction. Due to the large number of parameters involved, we can see many variations in the results. Thus, even for 2-D systems, there will always be an interest in developing more robust segmentation methods, new multiscale texture features and the application of innovative classification techniques. Some of the most interesting challenges are associated with emerging studies (see Section V). These methods can be used in order to focus on new 2-D problems associated with early plaque formation.

The extraction of 3-D shape and structure information can be used to further for our understanding of carotid plaque morphology. We believe that research will continue in establishing 3-D volumetric changes and their associations with atherosclerosis.

Plaque-motion analysis holds significant promise as well. The relative motion among different plaque components should be investigated. The future development of very accurate 3-D/4-D systems will also help with the development of accurate motion analysis systems.

It would be interesting to develop noninvasive, multimodality plaque-image analysis systems. The advancement of 3-D ultrasound will help these efforts. Basically, high-resolution 3-D ultrasound reconstructions will be much easier to fuse with 2-D slices from other modalities. To do this, we would need to register the geometric features of the 2-D slice to the 3-D volume or to use a mutual information registration method. It would also be interesting to examine how 2-D histological studies match 3 -D ultrasound reconstructions.

\section{REFERENCES}

[1] American Heart Association. (2007). Heart disease and stroke statistics2008, update, Dallas, TX, [Online]. Available: www.americanheart. org/presenter.jhtml

[2] World Health Organisation. (2007, Feb.). Fact sheet No. 317, [Online]. Available: Web page: www.who.int

[3] L. Reilly, R. Lusby, L. Hughes, L. Ferrell, R. Stoney, and W. Ehrenfeld, "Carotid plaque histology using real-time ultrasonography: Clinical and therapeutic implications," Amer. J. Surg., vol. 146, pp. 188-193, 1983.

[4] G. Belcaro, A. Nicolaides, G. Laurora, M. Rosaria, C. M. De Sanctis, L. Incandela, and A. Barsotti, "Ultrasound morphology classification of the arterial wall and cardiovascular events in a 6-year follow-up study," Arterioscler. Thromb. Vasc. Biol., vol. 16, pp. 851-856, 1996.

[5] A. Nicolaides, E. Shifrin, A. Bradbury, S. Dhanjil, M. Griffin, G. Belcaro, and M. Williams, "Angiographic and duplex grading of internal carotid stenosis: can we overcome the confusion?," J. Endovasc. Surg., vol. 3, pp. 158-165, 1996.

[6] G. Belcaro, G. Laurora, M. R. Cesarone, M. T. De Sanctis, L. Incandela, E. Fascetti, G. Geroulakos, G. Ramaswami, A. Pierangeli, and A. N. Nicolaides, "Ultrasonic classification of carotid plaques causing less than $60 \%$ stenosis according to ultrasound morphology and events," J. Cardiovasc. Surg., vol. 34, pp. 287-294, 1993.

[7] S. Ebrahim, O. Papacosta, P. Whincup, G. Wannamethee, M. Walker, A. N. Nicolaides, S. Dhanjil, M. Griffin, G. Belcaro, A. Rumley, and G. D. O. Lowe, "Carotid plaque, intima media thickness, cardiovascular risk factors, and prevalent cardiovascular disease in men and women: The British Regional Heart Study,”Stroke, vol. 30, pp. 841-850, 1999.
[8] O. Joakimsen, K. H. Bønaa, E. B. Mathiesen, E. Stensland-Bugge, and E. Arnesen, "Prediction of mortality by ultrasound screening of a general population for carotid stenosis: Troms $\emptyset$ study," Stroke, vol. 31, pp. 1871$1876,2000$.

[9] C. Schmidt, B. Fagerberg, J. Wikstrand, and J. Hulthe, On behalf of the RIS Study Group, "Multiple risk factor intervention reduces cardiovascular risk in hypertensive patients with echolucent plaques in the carotid artery," J. Int. Med., vol. 253, pp. 430-438, 2003.

[10] M. Mercuri, M. Bond, C. Sirtori, F. Veglia, G. Crepaldi, F. Saverio Feruglio, G. Descovich, G. Ricci, P. Rubba, and M. Mancini, "Pravastatin reduces carotid intima-media thickness progression in an asymptomatic hypercholesterolemic mediterranean population: The Carotid Atherosclerosis Italian Ultrasound Study," Amer. J. Med., vol. 101, pp. 627-634, 1996.

[11] L. E. Chambless, G. Heiss, A. R. Folsom, W. Rosamond, M. Szklo, R. Sharrett, and L. X. Clegg, "Association of coronary heart disease incidence with carotid arterial wall thickness and major risk factors: The Atherosclerosis Risk in Communities (ARIC) Study 1987-1993," Amer. J. Epidemiol., vol. 146, pp. 483-494, 1997.

[12] E. De Groote, J. W. Jukema, A. D. M. Van Swijndregt, A. H. Zwinderman, R. G. A. Ackerstaff, A. F. W. Van Der Steen, N. Bom, K. I. Lie, and A. V. G. Bruschke, "B-mode ultrasound assessment of pravastatin treatment effect on carotid and femoral artery walls and its correlations with coronary arteriographic findings: A report of the Regression Growth Evaluation Statin Study (REGRESS)," J. Amer. Coll. Cardiol., vol. 31, pp. 15611567, 1998.

[13] L. E. Chambless, A. R. Folsom, and L. X. Clegg, "Carotid wall thickness is predictive of incident clinical stroke: The Atherosclerosis Risk in Communities (ARIC) study," Amer. J. Epidemiol., vol. 151, pp. 478-487, 2000.

[14] L. E. Chambless, A. R. Folsom, L. X. Clegg, A. R. Sharrett, E. Shaha, F. J. Nieto, W. D. Rosamond, and G. Evans, "Six-year effect of combined vitamin $\mathrm{C}$ and $\mathrm{E}$ supplementation on atherosclerotic progression: The Antioxidant Supplementation in Atherosclerosis Prevention (ASAP) Study," Circulation, vol. 107, pp. 947-953, 2003.

[15] N. El-Barghouti, A. N. Nicolaides, T. Tegos, and G. Geroulakos, "The relative effect of carotid plaque heterogeneity and echogenicity on ipsilateral cerebral infarction and symptoms of cerebrovascular disease," Int. Angiol., vol. 15, no. 4, pp. 300-306, 1996.

[16] T. S. Elatrozy, A. N. Nicolaides, T. J. Tegos, and M. Griffin, "The objective characterisation of ultrasonic carotid plaque features," Eur. J. Vasc. Endovasc. Surg., vol. 16, no. 3, pp. 223-230, 1998.

[17] T. J. Tegos, P. Stavropoulos, M. M. Sabetai, P. Khodabakhsh, A. Sassano, and A. N. Nicolaides, "Determinants of carotid plaque instability: Echoicity versus heterogeneity," Eur. J. Vasc. Endovasc. Surg., vol. 22, pp. 22 30, 2001

[18] A. C. Gray-Weale, J. C. Graham, J. R. Burnett, K. Byrne, and R. J. Lusby, "Carotid artery atheroma: Comparison of preoperative B-mode ultrasound appearance with carotid endarterectomy specimen pathology," J. Cardiovasc. Surg., vol. 29, pp. 676-681, 1988.

[19] J. A. C. Arnold, K. B. Modaresi, N. Thomas, P. R. Taylor, and T. S. Padayachee, "Carotid plaque characterization by duplex scanning. Observer error may undermine current clinical trials," Stroke, vol. 30, no. 1 , pp. 61-65, 1999.

[20] T. F. O’Donnell, Jr., L. Erdoes, W. C. Mackey, J. McCullough, A. Shepard, P. Heggerick, J. Isner, and A. D. Callow, "Correlation of B-mode ultrasound imaging and arteriography with pathologic findings at carotid endarterectomy," Arch. Surg., vol. 120, no. 4, pp. 443-449, 1985.

[21] M. I. Aldooril, R. N. Baird, S. Z. Al-Sam, S. E. Cole, S. Mera, and J. D. Davies, "Duplex scanning and plaque histology in cerebral ischaemia," Eur, J. Vasc. Surg., vol. 1, pp. 159-164, 1987.

[22] A. L. Leahy, P. T. McCollum, T. M. Feeley, M. Sugrue, M. C. Grouden, D. J. O'Connell, D. J. Moore, and G. D. Shanik, "Duplex ultrasonography and selection of patients for carotid endarterectomy: Plaque morphology or luminal narrowing?" J. Vasc. Surg., vol. 8, no. 5, pp. 558-562, 1988.

[23] M. Langsfeld, A. C. Gray-Weale, and R. J. Lusby, "The role of plaque morphology and diameter reduction in the development of new symptoms in asymptomatic carotid arteries," J. Vasc. Surg., vol. 9, no. 4, pp. 548-557, 1989.

[24] B Widder, K Paulat, J. Hackspacher, H. Hamann, S. Hutschenreiter, C. Kreutzer, F. Ott, and J. Vollmar, "Morphological characterization of carotid artery stenoses by ultrasound duplex scanning," Ultrasound Med. Biol., vol. 16, no. 4, pp. 349-354, 1990.

[25] European carotid plaque study group, "Carotid artery plaque composition-Relationship to clinical presentation and ultrasound Bmode imaging," Eur. J. Vasc. Endovasc. Surg., vol. 10, pp. 23-30, 1995. 
[26] R. Kagawa, K. Moritake, T. Shima, and Y. Okada, "Validity of B-mode ultrasonographic findings in patients undergoing carotid endarterectomy in comparison with angiographic and clinicopathologic features," Stroke, vol. 27, no. 4, pp. 700-705, 1996.

[27] D. G. Kardoulas, A. N. Katsamouris, P. T. Gallis, T. P. Philippides, N. K. Anagnostakos, D. S. Gorgoyannis, and N. C. Gourtsoyannis, "Ultrasonographic and histologic characteristics of symptom-free and symptomatic carotid plaque," Cardiovasc. Surg., vol. 4, pp. 580-590, 1996.

[28] A. F. AbuRahma, P. D. Kyer, P. A. Robinson, and R. S. Hannay, "The correlation of ultrasonic carotid plaque morphology and carotid plaque hemorrhage: Clinical implications," Surgery, vol. 124, no. 4, pp. 721728, 1998.

[29] B. Lal, R. Hobson II, P. Pappas, R. Kubicka, M. Hameed, E. Chakhtura, Z. Jamil, F. Padberg Jr., P. Haser, and W. Durán, "Pixel distribution analysis of B-mode ultrasound scan images predicts histologic features of atherosclerotic carotid plaques," J. Vasc. Surg., vol. 35, no. 6, pp. 1210$1217,2002$.

[30] A. N. Nicolaides, S. K. Kakkos, M. Griffin, M. Sabetai, S. Dhanjil, T. Tegos, D. J. Thomas, A. Giannoukas, G. Geroulakos, N. Georgiou, S. Francis, E. Ioannidou, and C. J. Doré, "Severity of asymptomatic carotid stenosis and risk of ipsilateral ischaemic events: Results from the ACSRS study," Eur. J. Vasc. Endovasc. Surg., vol. 30, pp. 275-284, 2005.

[31] G. Geroulakos, G. Ramaswami, A. Nicolaides, K. James, N. Labropoulos, G. Belcaro, and M. Holloway, "Characterisation of symptomatic and asymptomatic carotid plaques using high-resolution real-time ultrasonography," Br. J. Surg., vol. 80, no. 10, pp. 1274-1277, 1993.

[32] J. M. Johnson, M. M. Kennelly, D. Decesare, S. Morgan, and A. Sparrow, "Natural history of asymptomatic carotid plaque," Arch. Surg., vol. 120, no. 9, pp. 1010-1012, 1985.

[33] J. M. de Bray, J. M. Baud, and M. Dauzat, on behalf of the Consensus Conference, "Consensus concerning the morphology and the risk of carotid plaques," Cerebrovasc. Dis., vol. 7, no. 5, pp. 289-296, 1997.

[34] J. F. Polak, L. Shemanski, D. H. O'Leary, D. Lefkowitz, T. R. Price, P. J. Savage, W. E. Brant, and C. Reid, "Hypoechoic plaque at US of the carotid artery: An independent risk factor for incident stroke in adults aged 65 years or older. Cardiovascular Health Study," Radiology, vol. 208, no. 3, pp. 649-654, 1998.

[35] M. K. Wolverson, H. M. Bashiti, and G. J. Peterson, "Ultrasonic tissue characterization of atheromatous plaques using a high resolution real time scanner," Ultrasound Med. Biol., vol. 9, pp. 599-609, 1983.

[36] B. L. Thiele, A. M. Jones, R. W. Hobson, D. F. Bandyk, W. H. Baker, D. S. Sumner, and R. B. Rutherford, "Standards in noninvasive cerebrovascular testing. Report from the committee on standards for noninvasive vascular testing of the joint council of the society for vascular surgery and the north American chapter of the international society for cardiovascular surgery," J. Vasc. Surg., vol. 15, no. 3, pp. 495-503, 1992.

[37] L. M. Pedro, M. M. Pedro, I. Gonçalves, T. F. Carneiro, C. Balsinha, R. Fernandes e Fernandes, and J. Fernandes e Fernandes, "Computerassisted carotid plaque analysis: Characteristics of plaques associated with cerebrovascular symptoms and cerebral infarction," Eur. J. Vasc. Endovasc. Surg., vol. 19, no. 2, pp. 118-123, Feb. 2000.

[38] E. Fosse, S. H. Johnsen, E. Stensland-Bugge, O. Joakimsen, E. B. Mathiesen, E. Arnesen, and I. Njølstad, "Repeated visual and computer-assisted carotid plaque characterization in a longitudinal population-based ultrasound study: The Tromso study," Ultrasound Med. Biol., vol. 32, pp. 3-11, 2006.

[39] M. M. Sabetai, T. J. Tegos, A. N. Nicolaides, S. Dhanjil, G. J. Pare, and J. M. Stevens, "Reproducibility of computer-quantified carotid plaque echogenicity: Can we overcome the subjectivity?" Stroke, vol. 31, no. 9, pp. 2189-2196, Sep. 2000.

[40] M. Griffin, A. Nicolaides, and E. Kyriacou, "Normalisation of ultrasonic images of atherosclerotic plaques and reproducibility of grey scale median using dedicated software," Int. Angiol., vol. 26, no. 4, pp. 372-377, Dec. 2007.

[41] T. J. Tegos, M. M. Sabetai, A. N. Nicolaides, G. Pare, T. S. Elatrozy, S. Dhanjil, and M. Griffin, "Comparability of the ultrasonic tissue characteristics of carotid plaques," J. Ultrasound Med., vol. 19, no. 6, pp. 399407, 2000

[42] T. Elatrozy, A. Nicolaides, T. J. Tegos, A. Z. Zarka, M. Griffin, and M. Sabetai, "The Effect of B-mode ultrasonic image standardization of the echodensity of symptomatic and asymptomatic carotid bifurcation plaque," Int. Angiol., vol. 17, no. 3, pp. 179-186, Sep. 1998.

[43] J. E. Wilhjelm, M. S. Jensen, S. K. Jespersen, B. Sahl, and E. Falk, "Visual and quantitative evaluation of selected image combination schemes in ultrasound spatial compound scanning," IEEE Trans. Med. Imag., vol. 23, no. 2, pp. 181-190, 2004.
[44] C. B. Burckhardt, "Speckle in ultrasound B-mode scans," IEEE Trans. Sonics Ultrason., vol. SU-25, no. 1, pp. 1-6, Jan. 1978.

[45] J. W. Goodman, "Some fundamental properties of speckle," J. Opt. Soc. Amer, vol. 66, no. 11, pp. 1145-1149, 1976.

[46] Y. Yongiian and S. T. Acton, "Speckle reducing anisotropic diffusion," IEEE Trans. Image Process., vol. 11, no. 11, pp. 1260-1270, Nov. 2002.

[47] J. A. Noble and A. Boukerroui, "Ultrasound image segmentation: A survey," IEEE Trans. Med. Imag., vol. 25, no. 8, pp. 987-1010, Jul. 2006.

[48] S. Gupta, L. Kaur, R. C. Chauhan, and S. C. Saxena, "A versatile technique for visual enhancement of medical ultrasound images," Digital Signal Process., vol. 17, no. 3, pp. 542-560, 2007.

[49] R. F. Wagner, S. W. Smith, J. M. Sandrik, and H. Lopez, "Statistics of speckle in ultrasound B-scans," IEEE Trans. Sonics Ultrason., vol. SU-30, no. 3, pp. 156-163, May 1983.

[50] J. S. Lee, "Digital image enhancement and noise filtering by use of local statistics," IEEE Trans. Pattern Anal. Mach. Intell., vol. PAMI-2, no. 2, pp. 165-168, Mar. 1980.

[51] J. C. Bamber and C. Daft, "Adaptive filtering for reduction of speckle in ultrasonic pulse-echo images," Ultrasonics, vol. 24, no. 1, pp. 41-44, 1986.

[52] C. P. Loizou and C. S. Pattichis, Despeckle Filtering Algorithms and Software for Ultrasound Imaging, (Synthesis Lectures on Algorithms and Software for Engineering). San Rafael, CA: Morgan \& Claypool Publishers, 2008.

[53] C. P. Loizou, C. S. Pattichis, M. Pantziaris, T. Tyllis, and A. Nicolaides, "Quality evaluation of ultrasound imaging in the carotid artery based on normalisation and speckle reduction filtering," Med. Biol. Eng. Comput., vol. 44, no. 5, pp. 414-426, 2006.

[54] C. P. Loizou, C. S. Pattichis, M. Pantziaris, T. Tyllis, and A. Nicolaides, "Snakes based segmentation of the common carotid artery intima media," Med. Biol. Eng. Comput., vol. 45, no. 1, pp. 35-49, 2007.

[55] C. P. Loizou, C. S. Pattichis, M. Pantziaris, and A. Nicolaides, "An integrated system for the segmentation of atherosclerotic carotid plaque," IEEE Trans. Inf. Technol. Biomed., vol. 11, no. 6, pp. 661-667, Nov. 2007.

[56] C. P. Loizou, C. S. Pattichis, C. I. Christodoulou, R. S. H. Istepanian, M. Pantziaris, and A. Nicolaides, "Comparative evaluation of despeckle filtering in ultrasound imaging of the carotid artery," IEEE Trans. Ultrason., Ferroelectr., Freq. Control, vol. 52, no. 10, pp. 1653-1669, Oct. 2005.

[57] C. I. Christodoulou, E. Kyriacou, C. S. Pattichis, and A. Nicolaides, "Multiple feature extraction for content-based image retrieval of carotid plaque ultrasound images," in Proc. ITAB2006 Conf, Ioannina, Greece, Oct. 2006, pp. 26-28.

[58] D. Cheng, A. Schmidt-Trucksaess, K. Cheng, and H. Burkhardt, "Using snakes to detect the intimal and adventitial layers of the common carotid artery wall in sonographic images," Comput. Methods Programm. Biol., vol. 67 , no. 1, pp. 27-37, 2002.

[59] N. Santhiyakumari and M. Madheswaran, "Extraction of intima- media layer of arteria- carotis and evaluation of its thickness using active contour approach," in Proc. Int. Conf. Intell. Adv. Syst., 25-28 Nov. 2007, pp. 582586.

[60] I. Wendelhag, Q. Liang, T. Gustavsson, and J. Wikstrand, "A new automated computerized analysing system simplifies reading and reduces the variability in ultrasound measurement of intima media thickness," Stroke, vol. 28, pp. 2195-2200, 1997.

[61] Q. Liang, I. Wendelhag, J. Wilkstrand, and T. A. Gustavsson, "Multiscale dynamic programming procedure for boundary detection in ultrasonic artery images," IEEE Trans. Med. Imag., vol. 19, no. 2, pp. 127-142, Feb. 2000

[62] F. Mao, J. Gill, D. Downey, and A. Fenster, "Segmentation of carotid artery in ultrasound images: Method development and evaluation technique," Med. Phys., vol. 27, no. 8, pp. 1-10, 2000.

[63] A. Zahalka and A. Fenster, "An automated segmentation method for three-dimensional carotid ultrasound images," Phys. Med. Biol., vol. 46, pp. 1321-1342, 2001.

[64] R. H. Selzer, W. J. Mack, P. L. Lee, H. Kwong-Fu, H. N. Hodis, "Improved common carotid elasticity and intima-media thickness measurements from computer analysis of sequential ultrasound frames," Atherosclerosis, vol. 154, no. 1, pp. 185-193, 2001.

[65] M. Gutierrez, P. Pilon, S. Lage, L. Kopel, R. Carvalho, and S. Furuie, "Automatic measurement of carotid diameter and wall thickness in ultrasound images," Comput. Cardiol., vol. 29, pp. 359-362, 2002.

[66] J. H. Stein, C. E. Korcarz, M. E. Mays, P. S. Douglas, M. Palta, H. Zhang, T. LeCaire, D. Paine, D. Gustafson, and L. Fan, "A semiautomated ultrasound border detection program that facilitates clinical measurement of 
ultrasound carotid intima-media thickness," J. Amer. Soc. Echocardiogr., vol. 18, no. 3, pp. 244-251, 2005.

[67] S. Delsanto, F. Mollinari, P. Giustetto, W. Liboni, S. Badalamenti, and J. S. Suri, "Characterization of a completely user-independent algorithm for carotid artery segmentation in 2-D ultrasound images," IEEE Trans. Instrum. Meas., vol. 56, no. 4, pp. 1265-1274, Aug. 2007.

[68] F. Faita, V. Gemignani, E. Bianchini, C. Giannarelli, L. Ghiadoni, and M. Demi, "Real-time measurement system for evaluation of the carotid intima-media thickness with a robust edge operator," J. Ultrasound Med., vol. 27, no. 9, pp. 1353-1361, 2008.

[69] A. Nicolaides, M. Sabetai, S. M. Kakkos, S. Dhanjil, T. Tegos, J. M. Stevens, D. J. Thomas, S. Francis, M. Griffin, G. Geroulakos, E. Ioannidou, and E. Kyriacou, "The asymptomatic, carotid, stenosis and risk of stroke (ACSRS) study," Int. Angiol., vol. 22, no. 3, pp. 263-272, 2003.

[70] A. K. Hamou and M. R. Ei-Sakka, "A novel segmentation technique for carotid ultrasound images," in Proc. Int. Conf. Acoust. Speech Signal Process., 2004, vol. III, pp. 521-524.

[71] A. R. Abdel-Dayen and M. R. Ei-Sakka, "A novel morphological-based carotid artery contour extraction," in Proc. Can. Conf. Electr. Comput. Eng., vol. 4, pp. 1873-1876, May 2004.

[72] S. Delsanto, F. Molinari et al., "User-independent plaque characterization and accurate IMT measurement of carotid artery wall using ultrasound," in Proc. 28th Ann. Int. Conf. IEEE EMBS, New York, Aug. 30-Sep. 3, 2006, pp. 2404-2407.

[73] J. Guerrero, and S. E. Salcudean et al., "Real-time vessel segmentation and tracking for ultrasound imaging applications," IEEE Trans. Med. Imag., vol. 26, no. 8, pp. 1079-1090, Aug. 2007.

[74] G. Slabaugh, G. Unal, M. Wels, T. Fang, and B. Rao, "Statistical regionbased segmentation of ultrasound images," Ultrasound Med. Biol., vol. 35, no. 5 , pp. 781-795, 2009 .

[75] G. Geroulakos, J. Domjan, A. Nicolaides, J. Stevens, N. Labropoulos, G. Ramaswami, and G. Belcaro, "Ultrasonic carotid artery plaque structure and the risk of cerebral infraction on computed tomography," J. Vasc. Surg., vol. 20, no. 2, pp. 263-266, Aug. 1994.

[76] N. El-Barghouty, G. Geroulakos, A. Nicolaides, A. Androulakis, and V. Bahal, "Computer assisted carotid plaque characterisation," Eur. J. Vasc. Endovasc. Surg., vol. 9, pp. 548-557, 1995.

[77] A. I. Iannuzzi, T. Wilcosky et al., "Ultrasonografic correlates of carotid atherosclerosis in transient ischemic attack and stroke," Stroke, vol. 26, no. 4, pp. 614-619, Apr. 1995.

[78] C. I. Christodoulou, C. S. Pattichis, M. Pantziaris, and A. Nicolaides, "Texture based classification of atherosclerotic carotid plaques," IEEE Trans. Med. Imag., vol. 22, no. 7, pp. 902-912, Jul. 2003.

[79] F. Rakebrandt, D. C. Crawford, D. Havard, D. Coleman, and J. P. Woodcock, "Relationship between ultrasound texture classification images and histology of atherosclerotic plaque," Ultrasound Med. Biol., vol. 26, no. 9, pp. 1393-1402, 2000.

[80] S. K. Kakkos, J. M. Stevens, A. N. Nicolaides, E. Kyriacou, C. S. Pattichis, G. Geroulakos, and D. Thomas, "Texture analysis of ultrasonic images of symptomatic carotid plaques can identify those plaques associated with ipsilateral embolic brain infarction," Eur. J. Vasc. Endovasc. Surg., vol. 33, no. 4, pp. 422-429, 2007.

[81] S. G. Mougiakakou, S. Golemati, I. Gousias, A. Nicolaides, and K. Nikita, "Computer-aided diagnosis of carotid atherosclerosis based on ultrasound image statistics, laws' texture and neural networks," Ultrasound Med. Biol., vol. 33, no. 1, pp. 26-36, 2007.

[82] E. C. Kyriacou, C. S. Pattichis, M. A. Karaolis, C. P. Loizou, C. T. Christodoulou, M. S. Pattichis, S. Kakkos, and A. Nicolaides "An medicine and biology magazine," Special Issue on Image, Signal and Distributed Data Processing for Networked e-Health Applications, vol. 26, no. 5, pp. 43-50, Sep./Oct. 2007.

[83] E. Kyriacou, M. Pattichis, C. S. Pattichis, A. Mavrommatis, C. I. Christodoulou, S. Kakkos, and A. Nicolaides, "Classification of atherosclerotic carotid plaques using morphological analysis on ultrasound images," J. Appl. Intell., vol. 30, no. 1, pp. 3-23, 2009.

[84] M. Amadasun and R. King, "Textural features corresponding to textural properties," IEEE Trans. Syst., Man, Cybern., vol. 19, no. 5, pp. 12641274, Sep./Oct. 1989.

[85] E. R. Dougherty, An Introduction to Morphological Image Processing. Belingham, Washington: SPIE Optical Engineering Press, 1992.

[86] E. R. Dougherty and J. Astola, An Introduction to Nonlinear Image Processing. Belingham, Washington: SPIE Optical Engineering Press, 1994.

[87] J. E. Wilhjelm, L. M. Gronholdt, B. Wiebe, S. K Jespersen, L. K. Hansen, and H. Sillesen, "Quantitative analysis of ultrasound b-mode images of carotid atherosclerotic plaque: Correlation with visual classification and histological examination," IEEE Trans. Med. Imag., vol. 17, no. 6, pp. 910-922, Dec. 1998

[88] P. Asvestas, S. Golemati, G. K. Matsopoulos, K. S. Nikita, and A. Nicolaides, "Fractal dimension estimation of carotid atherosclerotic plaques from B-mode ultrasound: A pilot study," Ultrasound Med. Biol., vol. 28, no. 9, pp. 1129-1136, Sep. 2002.

[89] P. Holdfeldt, "Ultrasound image analysis for automated classification of atherosclerotic plaque in the human carotid artery," Licentiate of Engineering thesis, Chalmers Univ. Technol., Goteborg, Sweden, 2007.

[90] A. Landry, J. D. Spence, and A. Fenster, "Measurement of carotid plaque volume by 3-dimensional ultrasound," Stroke, vol. 35, no. 4, pp. 864-869, 2004.

[91] B. Chiu, M. Egger, J. D. Spence, G. Parraga, and A. Fenster, "Quantification of carotid vessel wall and plaque thickness change using 3D ultrasound images," Med. Phys., vol. 35, no. 8, pp. 3691-3710, Aug. 2008.

[92] B. Chiu, M. Egger, J. D. Spence, G. Parraga, and A. Fenster, "Development of 3D ultrasound techniques for carotid artery disease assessment and monitoring," Int. J. CARS, vol. 3, pp. 1-10, 2008.

[93] S. Meairs and M. Hennerici, "Four-dimensional ultrasonographic characterization of plaque surface motion in patients with symptomatic and asymptomatic carotid artery stenosis," Stroke, vol. 30, pp. 1807-1813, 1999.

[94] S. E. Murillo, M. S. Pattichis, C. P. Loizou, C. S. Pattichis, E. Kyriacou, A. G. Constantinides, and A. Nicolaides, "Atherosclerotic plaque motion trajectory analysis from ultrasound videos," in CD-Rom Proc. 5th IEEE EMBS Spec. Topic Conf. Inf. Tech. Biomed., Oct. 2006, p. 5.

[95] V. Murray, S. E. Murillo, C. P. Loizou, C. S. Pattichis, E. Kyriacou, and A. Nicolaides, "An AM-FM model for motion estimation in atherosclerotic plaque videos," in Proc. 41 st Asilomar Conf. Signals, Syst. Comput., Nov. 4-7, 2007, pp. 746-750.

[96] S. Golemati, J. Stoitsis, and K. S. Nikita, "Motion analysis of the carotid artery wall and plaque using B-mode ultrasound," Vasc. Disease Prevent., vol. 4, no. 4, pp. 296-302, Nov. 2007.

[97] J. Stoitsis, S. Golemati, and K. S. Nikita, "A modular software system to assist interpretation of medical images-Application to vascular ultrasound images," IEEE Trans. Instrum. Meas., vol. 55, no. 6, pp. 1944-1952, Dec. 2006

[98] J. Stoitsis, S. Golemati, E. Bastouni, and K. S. Nikita, "A mathematical model of the mechanical deformation of the carotid artery wall and its application to clinical data," in Proc. 29th Ann. IEEE EMBS Conf., Aug. 2007, pp. 2163-2166.

[99] C. Scmitt, G. Soulez, R. L. Maurice, M. F. Giroux, and G. Cloutier, "Noninvasice vascular elastography: Toward a complementary characterization tool of atherosclerosis in carotid arteries," Ultrasound Med. Biol., vol. 33, no. 12, pp. 1841-1858, 2007.

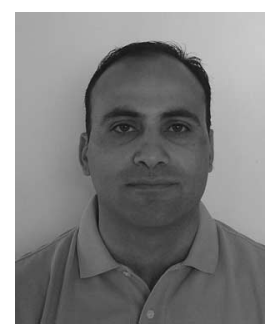

Efthyvoulos C. Kyriacou (S'96-M'01) received the Diploma degree in electrical and computer engineering and the Ph.D. degree from the Department of Electrical and Computer Engineering, National Technical University of Athens, Greece, in 1996 and 2000, respectively.

From 1996 to 2008, he was involved in a number of collaborations in both Greece and Cyprus. He is currently an Associate Professor in the Department of Computer Science and Engineering, Frederick University, Limassol, Cyprus. He has authored or coauthored 20 refereed journal, 64 conference papers, and 13 chapters in books in these areas. His research interests include e-health systems, medical imaging systems, and intelligent systems applications in medicine. He has been involved in numerous projects in these areas funded by EU, the National Research Foundation of Cyprus, the INTERREG, and other bodies. He was a Reviewer in many journals related to his research fields.

Dr. Kyriacou has been an Associate Editor of the IEEE TRANSACTION ON INFORMATION TECHNOLOGY IN BIOMEDICINE since 2007. He was Guest Co-Editor of the Special Issues on the Computational Intelligence in Medical Systems and the Biomedical Informatics of THE IEEE TRANSACTIONS ON INFORMATION TECHNOLOGY IN BIOMEDICINE. 


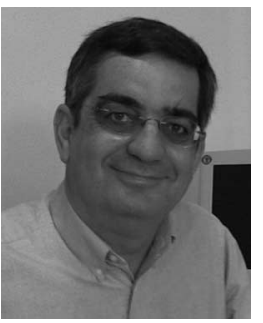

Constantinos Pattichis (S'88-M'88-SM'99) was born in Cyprus on Jan 30, 1959. He received the Diploma as technician engineer from the Higher Technical Institute, Nicosia, Cyprus, in 1979, the B.Sc. degree in electrical engineering from the University of New Brunswick, Canada, in 1983, the M.Sc. degree in biomedical engineering from the University of Texas at Austin, in 1984, the M.Sc. degree in neurology from the University of Newcastle Upon Tyne, U.K., in 1991, and the Ph.D. degree in electronic engineering from the University of London, London, U.K., in 1992

He is currently Professor with the Department of Computer Science of the University of Cyprus, Nicosia. His research interests include e-health, medical imaging, biosignal analysis, and intelligent systems. He has been involved in numerous projects in these areas funded by EU, the National Research Foundation of Cyprus, the INTERREG, and other bodies, with a total funding managed in excess of 5 million Euros. He was on the Editorial Board of the Journal of Biomedical Signal Processing and Control. He is the Co-Editor of the books the M-Health: Emerging Mobile Health Systems (New York: Springer, 2006) and the Information Technology in Biomedicine (IEEE, to be published in 2010). He is the coauthor of the monograph Despeckle Filtering Algorithms and Software for Ultrasound Imaging (San Rafael, CA: Morgan \& Claypool, 2008). He has authored or coauthored 52 refereed journal and 142 conference papers, and 19 chapters in books in these areas.

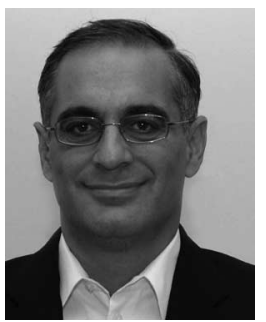

Marios Pattichis (M'99-SM'06) received the B.Sc. (high honors and special honors) degree in computer sciences and the B.A. (high honors) degree in mathematics, in 1991, the M.S. degree in electrical engineering, in 1993, and the Ph.D. in computer engineering, in 1998, all from the University of Texas at Austin, Austin.

$\mathrm{He}$ is currently an Associate Professor in the Department of Electrical and Computer Engineering, University of New Mexico (UNM), Albuquerque, where he is also an Associate Professor in the Department of Radiology. He is an Associate Editor of the Pattern Recognition. His research interests include digital image, and video processing and communications, dynamically reconfigurable computer architectures, and biomedical and space image processing applications.

Dr. Pattichis is an Associate Editor of the IEEE TRANSACTIONS ON INDUSTRIAL INFORMATICS. He was the General Chair of the 2008 IEEE Southwest Symposium on image analysis and interpretation. He was a recipient of the 2004 Electrical and Computer Engineering Distinguished Teaching Award and the 2006 School of Engineering Harrison Faculty Recognition Award at UNM.

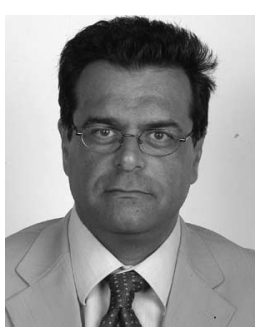

Christos Loizou (M'05) received the B.Sc. degree in electrical engineering and the Dipl.-Ing. (M.Sc.) degree in computer science and telecommunications from the University of Kaisserslautern, Kaisserslautern, Germany, in 1986 and 1990, respectively, and the Ph.D. degree on ultrasound image analysis of the carotid artery from the Department of Computer Science, Kingston University, London, U.K., in 2005.

From 1996 to 2000, he was a Lecturer in the Department of Computer Science, Higher Technical Institute, Nicosia, Cyprus. Since 2000, he is an Assistant Professor in the Department of Computer Science, School of Sciences and Engineering, Intercollege, Cyprus. From 1990 to 1996, he was a Manager of a telecommunications company. He was a Supervisor of a number of Ph.D. and B.Sc. students in the area of computer image analysis and telemedicine. He is also an Associated Researcher at the Institute of Neurology and Genetics, Nicosia, Cyprus. He has authored or coauthored book Despeckle Filtering Algorithms and Software for Ultrasound Imaging, eight chapters in books, 11 referred journal, and 40 conference papers in the fields of image and video analysis. His research interests include medical imaging and processing, motion and video analysis, signal and image processing, pattern recognition, biosignal analysis, in ultrasound, magnetic resonance, and optical coherence tomography imaging and computer applications in medicine.

Dr. Loizou is a Senior Member of the IEE.

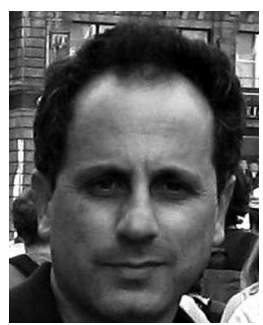

Christodoulos Christodoulou received the diploma degree in electrical engineering with specialization in telecommunications from the Technical University RWTH Aachen, Aachen, Germany, in 1987, and the $\mathrm{Ph} . \mathrm{D}$. degree in electronics engineering from the Queen Mary, University of London, London, U.K., in 2000 .

He is currently a Researcher with the Department of Computer Science, University of Cyprus, Nicosia, Cyprus and with the Department of Computational Intelligence, Cyprus Institute of Neurology and Genetics. His research interests include intelligent information systems, artificial neural networks, signal and image processing, pattern recognition, biosignal analysis, and computer applications in medicine and meteorology. His research work in the aforementioned areas has been published in a number of refereed journal papers, book chapters, and conference papers.

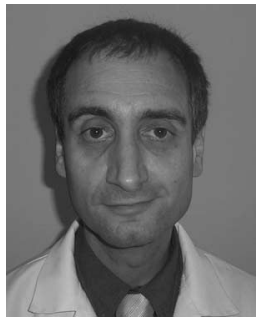

Stavros K. Kakkos received the medical degree (with honors) from the University of Patras, Patras, Greece, the Doctorate degree in medicine and the general surgery training from the University of Patras, in 1995 and 1997, respectively, the M.Sc. degree in vascular technology and medicine from the University of London, London, U.K., in 1999 through the Alexander S. Onassis Public Benefit Foundation scholarship, and the Ph.D. degree from the Department of Vascular Surgery, Imperial College, University of London, in 2004 .

From 2004 to 2007, he was involved in clinical training in vascular surgery, in U.K. and U.S. He is currently an Assistant Professor of vascular surgery in the Department of Vascular Surgery, University of Patras Medical School, Patras. $\mathrm{He}$ has so far participated in five multicentre studies, authored or coauthored more than 80 papers in peer-reviewed journals, and also contributed in more than 90 conference presentations and eight book chapters.

Dr. Kakkos has received numerous awards and distinctions for his clinical and research activities.

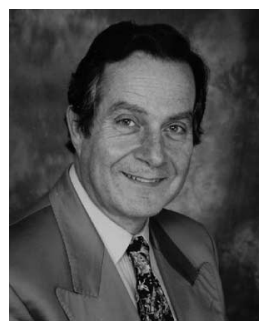

Andrew Nicolaides graduated from Guy's Hospital Medical School, London University, London, U.K., in 1962. He received the M.S. degree from the Royal College of Surgeons of England, London, U.K., and the F.R.C.S., and F.R.C.S.E. degrees from the Royal College of Surgeons of England, London, and the Royal College of Surgeons of Edinburgh, Midlothian, U.K., in 1967.

He was with Oxford University, Kings College Hospital Medical School and St Mary's Hospital Medical School, London for higher surgical training. He was a Professor of Vascular Surgery at the Imperial College School of Medicine (St. Mary's Hospital), a Consultant Vascular Surgeon at St Mary's Hospital from 1983 to 2000, and a Medical Director at the Cyprus Institute of Neurology and Genetics from 2001 to 2004. His research group is known internationally in several areas, which include noninvasive vascular screening and diagnostic investigation, early detection and prevention of cardiovascular and venous disease. He is currently the Professor Emeritus at Imperial College, London and an Examiner for M.S. and Ph.D. degrees for London University, London. He is also a "Special Scientist" at the University of Cyprus, Nicosia, Cyprus, and the Medical Director of the Vascular Screening and Diagnostic Centre, London. His current research interests include the genetic risk factors for cardiovascular disease, identification of individuals at risk and the development of effective methods of prevention, especially stroke. He is Editor-in-Chief of International Angiology and is on the Editorial Board of many vascular journals. He has trained over 200 vascular surgeons who are practicing all over the world; 12 of them are holding prestigious Chairs as Professors in vascular surgery. He is the coauthor of more than 500 original papers and editor of 14 books. 